\title{
Adriano y el calendario imperial de juegos atléticos: propuesta sobre el tercer y cuarto año del ciclo olímpico ${ }^{1}$
}

\author{
Rocío Gordillo Hervás ${ }^{2}$
}

Recibido: 19 de febrero de 2016 / Aceptado: 21 de diciembre de 2016

Resumen. Este artículo intentará aportar una reconstrucción alternativa al tercer y cuarto año del calendario de juegos atléticos inscrito en la estela de Alejandría en la Tróade, siguiendo la línea de investigación de los editores de la estela, G. Petzl y E. Schwerteheim. El artículo se centrará en el interés del emperador Adriano por preservar los juegos Panateneos en su fecha tradicional en el tercer año del calendario a expensas de los juegos Píticos, que fueron movidos al cuarto año. Se explorará las consecuencias del traslado de los juegos Píticos en los juegos Ístmicos, quienes estaban íntimamente ligados a ellos, para intentar buscar una solución a la recurrente objeción de los investigadores sobre la inserción de los juegos Píticos en el cuarto año del ciclo olímpico.

Palabras clave: agon; juegos Píticos; juegos Panateneos; juegos Ístmicos.

\section{[en] Hadrian and the Imperial Calendar of Athletic Games: Proposal for the Third and Fourth Year of the Olympic Cycle}

\begin{abstract}
This article aims to provide an alternative reconstruction of the third and fourth year of Hadrian's calendar of athletic games from the stele in Alexandria Troad, by following the line of research of the stele's editors, G. Petzl and E. Schwerteheim. The focus will be on Hadrian's attempt to preserve the Panathenaic games' traditional timeline in the third year of the calendar at the expense of the Pythian games, which were shifted to the fourth. The article will explore the consequences of the displacement of the Pythian games and of the associated Isthmic games, and will attempt to counter the recurring scholarly objections to the insertion of the Pythian games in the fourth year of the Olympic cycle.
\end{abstract}

Keywords: Agon; Pythian Games; Panathenaic Games; Isthmian Games.

Sumario. 1. Introducción. 2. La ubicación temporal de los juegos Panateneos en el calendario atlético adrianeo. 3. La ubicación temporal de los juegos Píticos en el calendario atlético adrianeo. 4. Consecuencias de la reubicación de los agones Píticos: los juegos Ístmicos. 5. Conclusiones.

Cómo citar: Gordillo Hervás, R. (2017) Adriano y el calendario imperial de juegos atléticos: propuesta sobre el tercer y cuarto año del ciclo olímpico, en Gerión 35/1, 117-140.

\footnotetext{
1 Este artículo se enmarca dentro del proyecto de la Universidad Pablo de Olavide Adriano y la integración de la diversidad regional. Una perspectiva histórica e historiográfica (HAR2015-65451-C2-1-P), 01/01/2016 31/12/2018.

2 Universidad Pablo de Olavide, Sevilla

E-mail: rgorher@upo.es
} 


\section{Introducción ${ }^{3}$}

La segunda carta inscrita en una estela hallada en la ciudad de Alejandría en la Tróa-

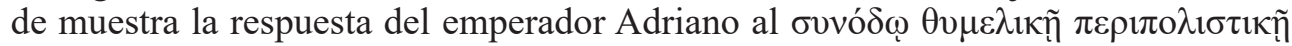

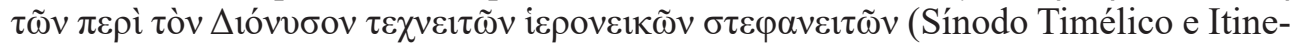
rante de los vencedores sagrados y coronados artistas de Dionisos) donde reorganiza el calendario agonístico del Imperio. Fechado en 134 d.C., el nuevo calendario se estructura en torno a un ciclo de cuatro años que se inicia con la celebración de los juegos Olímpicos y finaliza con los Panhelenos de Atenas. A pesar de la gran cantidad de estudios que se han llevado a cabo sobre la organización del calendario, actualmente persiste el debate académico sobre la ubicación temporal de los juegos Panateneos y los juegos Píticos. ${ }^{4}$ En el calendario tradicional, ambos juegos se celebraban en el tercer año olímpico. Los Panateneos tenían su día principal el 28 de Hecatombeón (julio-agosto) y los Píticos el 7 de Bucatio (agosto-septiembre). En el calendario adrianeo, el orden de los juegos estaría establecido de la siguiente manera: primero se desarrollarían los Panateneos, con una duración de cuarenta días; tras ellos los del Koinon de Asia en Esmirna, Pérgamo y Éfeso, de 141 días incluyendo el desplazamiento de los atletas entre las ciudades y, por último, los Píticos, de cuarenta días. Los más de cuatro meses de duración los juegos asiáticos imposibilitan que los concursos Panateneos y Píticos puedan mantener su ubicación temporal tradicional por lo que, probablemente, uno de ellos tuvo que ser desplazado en época adrianea.

Este problema ha llevado a los investigadores a dividirse en torno a dos hipótesis: 1) la iniciada por P. Gouw y seguida por J. Y. Strasser para quienes los juegos Píticos se mantienen en el calendario adrianeo el 7 de Bucatio del tercer año olímpico, por lo que los juegos Panateneos cambiarían su ubicación a la primavera del segundo año olímpico [véase Fig. 1], y 2) la iniciada por los primeros editores de la estela, G. Petzl y E. Schwerteheim, y seguida por J. L. Shear, que considera que el Emperador habría optado por mantener los juegos Panateneos el 28 de Hecatombeón del tercer año olímpico llevando al desplazamiento de los juegos Píticos hacia el cuarto año olímpico. El presente artículo intentará aportar una posible interpretación del tercer y cuarto año olímpico del calendario adrianeo siguiendo la línea de investigación iniciada por G. Petzl y E. Schwerteheim. Para ello se indagará en el interés del emperador Adriano por mantener los juegos Panateneos en su ubicación temporal tradicional en detrimento de los Píticos. Igualmente, se analizará las consecuencias de la reubicación de los juegos Píticos para otros concursos griegos, en especial los juegos Ístmicos de Corinto.

Una de las principales características del nuevo calendario atlético adrianeo es la claridad, exhaustividad y precisión del Emperador en la organización del tiempo. En algunas ocasiones se indica el día exacto de la celebración de los juegos atléticos, utilizando para ello el calendario "festivo" o arcontal ateniense o el calendario juliano romano. ${ }^{5}$ De este modo, el Emperador establece que los juegos Adrianeos de Atenas debían comenzar el día 1 Memacterión y, los juegos Actíacos nueve días antes de las calendas de octubre. Junto a ello, en el calendario se hace mención a la

Agradezco al profesor Cortés Copete su inestimable ayuda en la preparación de este artículo.

4 Petzl - Schwertheim 2006; Jones 2007; Gouw 2008; Slater 2008; Guerber 2009, 224-233; Schmidt 2009; Strasser 2010; Le Guen 2010, 213; Shear 2012.

5 De forma general, sobre el calendario en el mundo antiguo véase: SAMUEL 1972; FeENEY 2007; RüPKE 2011; STERN 2012; ForSYTHe 2012. 
duración, expresada en días, de los agones. Ejemplo de ello son los juegos Actíacos, los del Koinon de Asia en Esmirna, Pérgamo y Éfeso, y los juegos Adrianeos de Esmirna, que debían celebrarse en un plazo de 40 días. Por último, se indica el número de días que los participantes pueden emplear para viajar de una competición a otra. Así, tras los juegos del Koinon de Asia en Pérgamo, la ciudad de Éfeso debe esperar cuatro días "desde la carrera de armas del concurso de Pérgamo". ${ }^{6}$ El carácter exhaustivo del calendario se ilustra claramente en la mención de los juegos Panateneos y Píticos:

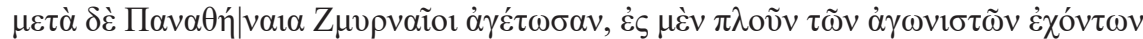

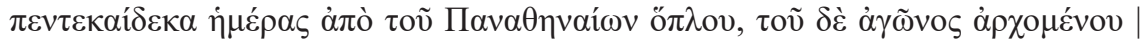

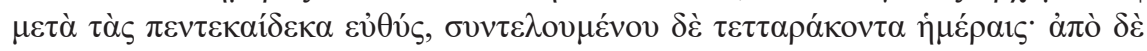

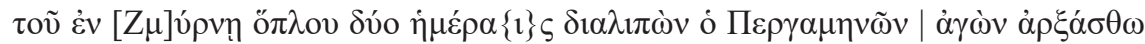

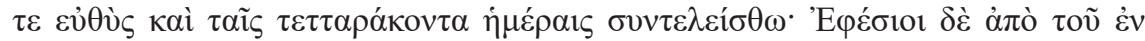

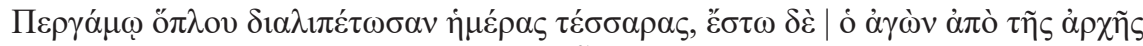

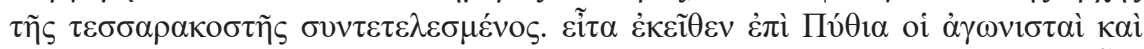

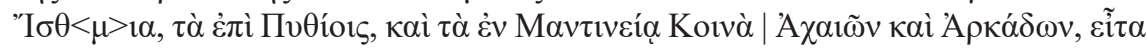

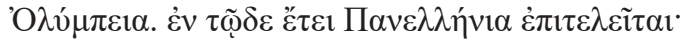

Tras los Panateneos serán los esmirnotas quienes celebren su festival, teniendo los concursantes quince días para el viaje por mar a partir de la carrera con armas de los Panateneos, puesto que los juegos comenzarán inmediatamente después de esos quince días y terminarán en otros cuarenta. Dejando pasar dos días desde la carrera con armas del concurso de Esmirna, deberá comenzar inmediatamente el concurso de Pérgamo y deberá terminar en cuarenta días. Los efesios dejarán pasar cuatro días desde la carrera de armas del concurso de Pérgamo, pero el concurso habrá de terminar en cuarenta días desde su comienzo. A continuación, los concursantes desde allí irán a los Píticos y los Ístmicos, los que se celebran tras los Píticos, y a los concursos del Koinon de los aqueos y arcadios que se celebran en Mantinea, y después, los Olimpeos. En este mismo año se celebrarán los Panhelenos. $^{7}$

\section{La ubicación temporal de los juegos Panateneos en el calendario atlético adrianeo}

La primera hipótesis anteriormente comentada establece que los juegos Panateneos cambian su celebración desde el verano del tercer año olímpico a la primavera del segundo (Fig. 1). P. Gouw indica que esta alteración es consecuencia de la voluntad del Emperador de insertar el circuito oriental (Koinon de Asia en Esmirna, Pérgamo y Éfeso) en el nuevo calendario atlético pero sobre todo del declive que experimentan los juegos Panateneos en época romana, indicando que "Not much is heard from the Panathenaean games until the second century AD". ${ }^{8}$ Para este investigador, el cambio de los Panateneos a la primavera del segundo año olímpico quedaría justifi-

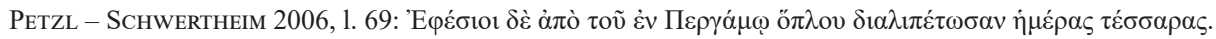

Id. 11. 66-71. Traducción de CORTÉs COPETE (e.p.).

Gouw 2008, 101. 
cado por la dedicatoria del discurso número 47 del sofista griego Himerio, del siglo IV d.C., donde se indica que los juegos Panateneos se celebran en primavera: "A Basilio, durante los Panateneos, al principio de primavera". ${ }^{9}$ De este modo, si los juegos Panateneos en época adrianea también se celebran en primavera, se resolvería el problema de la introducción de los juegos asiáticos, así como la celebración de los concursos Píticos en el tercer año olímpico. Sin embargo, considero que la hipótesis de P. Gouw debe ser revisada en sus dos argumentos principales. El único indicio que aporta el investigador para justificar el declive de los juegos Panateneos es la escasez de referencias en los palmareses atléticos. Este argumento depende claramente de las inscripciones que se han conservado hoy día, por lo que considero que no es un índice que pruebe la decadencia o no de un juego en época romana. De hecho, siguiendo el catálogo de inscripciones llevado a cabo por L. Moretti, el cómputo de inscripciones que hacen referencia a los juegos Panateneos se mantiene homogéneo desde época helenística hasta el siglo III d.C. ${ }^{10}$ Para poder hablar de decadencia, el número de inscripciones debería haber sufrido una disminución que no se observa. En segundo lugar, el traslado de los juegos desde verano a primavera se recoge tan sólo una vez en las fuentes literarias, la mencionada dedicación de Himerio que, además, es muy tardía con respecto al tiempo que nos ocupa. Es posible que este cambio se hubiera realizado en el siglo III d.C. y que siguieran manteniendo su lugar tradicional en época adrianea, es decir, el tercer año olímpico.

En el calendario adrianeo, se afirma que los juegos Panateneos se ubican: $\mu \varepsilon \tau \grave{\alpha} \delta \grave{\varepsilon}$

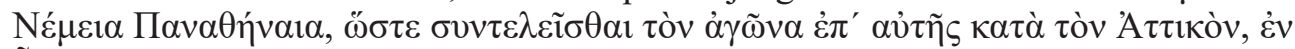

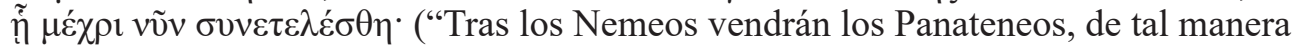
que la competición se celebre en la misma fecha, según el calendario ático, en la que hasta ahora ha venido celebrando"). ${ }^{11}$ El emperador Adriano indica expresamente que los juegos Panateneos deben realizarse en "la misma fecha" en la que hasta ahora se han estado organizando. Estos juegos conmemoraban el nacimiento de Atenea, fechado en el calendario ateniense el 28 de Hecatombeón (julio-agosto), día en el que se celebraba la procesión cívica que presentaba el peplos a la diosa en su templo. ${ }^{12}$ El hecho de que el Emperador no haga mención explícita de una fecha precisa para los Panateneos, como sí se encuentran para otros agones, mientras que recurre a la "tradición" podría demostrar que no hubo ningún cambio de fecha. De hecho, el trasvase de los juegos desde su fecha tradicional a primavera habría supuesto un problema religioso ya que se celebrarían las fiestas en honor a la diosa políada en un día que no se ajustaría a la conmemoración de su aniversario.

Los palmareses atléticos sugieren que los juegos Panateneos no suponían un problema para la inserción de las fiestas orientales, ya que se organizaban en otro periodo del año olímpico. En la inscripción del atleta Elio Aristómaco, oriundo de Magnesia del Meandro, las victorias en los agones aparecen ordenadas cronológicamente:

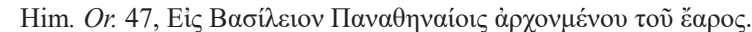

10 Moretti 1953, 279, en época helenística 5 inscripciones hacen referencia a victorias en los juegos Panateneos y en el siglo I d.C. tan sólo dos, mientras que durante el siglo II d.C. aparecen en 4 inscripciones y en el siglo III d.C. en 5.

11 Petzl - Schwertheim 2006, 11. 66-67.

12 Mikalson 1975, 34.
} 


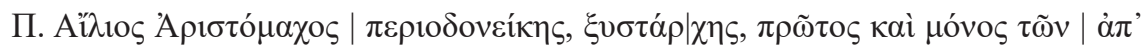

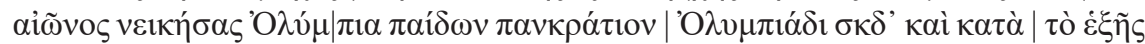

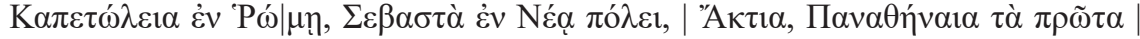

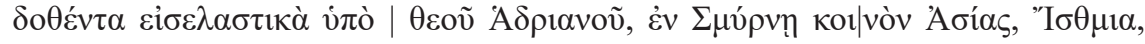

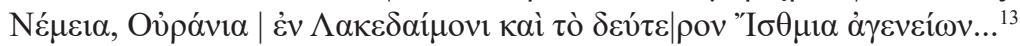

P. Elio Aristómaco campeón de la periodos, xystarca, primero y único en toda la historia en resultar vencedor del pancracio de Olimpia en (categoría de) niños, en la $224^{\circ}$ Olimpiada y después de los (juegos) Capitolinos de Roma, (juegos) Sebastos de Neapolis, (juegos) Actiacos, (juegos) Panateneos, los primeros tras haber recibido la condición iselástica del divino Adriano, en Esmirna (los juegos del) Koinon de Asia, (juegos) Ístmicos, (juegos) Nemeos, (juegos) Urania en Lacedemonia y por dos veces de los (juegos) Ístmicos...

La inscripción se podría fechar en época adrianea o antonina. J. L. Shear indica que los juegos Panateneos a los que aquí se refieren tuvieron lugar en el 123 d.C. ${ }^{14}$ Como se puede observar, tras los Panateneos aparecen los juegos del Koinon de Asia en Esmirna, según el calendario adrianeo, los primeros juegos que se celebran del circuito oriental. Si Elio Aristómaco compitió en los juegos Panateneos y en los juegos del Koinon de Asia en Esmirna, podría indicar que ambos concursos eran sucesivos en el tiempo, tal y como se establece en la carta del emperador Adriano. Frente a ello, no aparecen los Píticos que, como se verá en el siguiente apartado, coincidían en el calendario con los juegos de Esmirna.

La inscripción de Aristómaco muestra el interés del emperador Adriano por reformar los concursos de la ciudad de Atenas con motivo de integrarla en el circuito internacional de juegos y enaltecerla como uno de los centros principales de la actividad agonística del Imperio. Este hecho se fundamenta en el nuevo calendario atlético de Alejandría en la Tróade, donde Atenas es la ciudad que más juegos va a organizar durante el ciclo olímpico, cuatro en total: los Adrianeos, Olimpios, Panateneos y Panhelenos. El plan de actuación del Emperador para la exaltación agonística de la ciudad ateniense girará en torno a dos ejes principales: 1) Enaltecimiento del festival políado, los juegos Panateneos y 2) Creación de nuevos juegos atléticos. Tal y como reza en la inscripción, Elio Aristómaco es el primer atleta en ganar los primeros juegos Panateneos iselásticos, una concesión que sólo podía otorgar el emperador. Los ganadores en estas competiciones no sólo tenían derecho a la iselasis, es decir, la entrada triunfal en sus ciudades de origen, sino que también recibían honores especiales, tales como exenciones fiscales y pensiones monetarias. ${ }^{15} \mathrm{La}$ concesión imperial a los juegos Panateneos supondrá el renacer de los mismos. Van a cambiar su carácter cívico y regional para pasar a formar parte del circuito de agones internacional. El resurgir de los juegos coincidirá con la creación de una nueva era, a través de la cual se van a datar las victorias de los ganadores en las distintas disciplinas. Así por ejemplo, en el palmarés de T. Elio Aurelio Menandro, de la segunda mitad

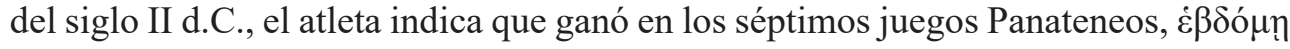

Inscr. Magn. 180-181. Traducción de la autora.

SHEAR 2012,160-161.

Pleket 1975; Remijsen 2011. 
$\Pi \alpha v \alpha \theta \eta v \alpha 1 \delta 1 .{ }^{16}$ Igualmente en el siglo III d.C. varios palmareses recogen victorias de atletas en $\operatorname{los} 29^{\circ}\left(\Pi \alpha v \alpha \theta \eta v \alpha i \delta 1 \kappa \theta^{\prime}\right)$ y $35^{\circ}\left(\Pi \alpha v \alpha \theta \varepsilon v \alpha 1 \delta \imath \lambda \varepsilon^{\prime}\right)$ juegos Panateneos. ${ }^{17}$ Sin duda este cómputo debería entenderse desde la reforma adrianea.

Con la concesión iselástica, los juegos Panateneos quedan equiparados a los agones que componían la archaia periodos quedando insertos en el nuevo circuito adrianeo. Sin embargo, no van a ser los únicos juegos atenienses que aparezcan en el calendario del Emperador. En las líneas 62-63 se indica, $\mu \varepsilon \tau \grave{\alpha} \delta \dot{\varepsilon} \tau \grave{\alpha}$ 'O $\lambda \hat{\mu} \mu \pi \imath$

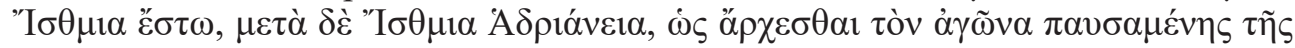

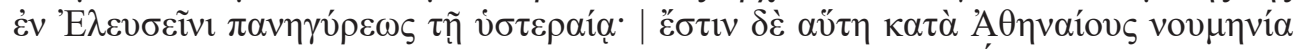

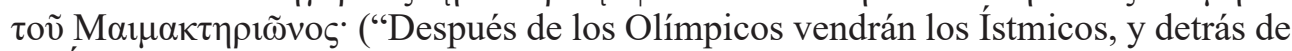
los Ístmicos, los Adrianeos, puesto que el concurso comienza al día siguiente de la fiesta que termina en Eleusis. Este día es, entre los atenienses, el primer día del mes de Memacterión") ${ }^{18}$ La cercanía en el tiempo entre la panegiris de Eleusis y los juegos Adrianeos podría indicar que estos últimos se celebrarían en un lugar próximo al santuario eleusino, ya que los atletas tan sólo disponen de un día para desplazarse de un sitio a otro. Por este motivo, es muy probable que los juegos Adrianeos sean aquellos que se organizan en la ciudad de Atenas. Sobre la panegiris de Eleusis, los editores de las cartas de Alejandría en la Tróade, G. Petzl y E. Schwertheim, concluyen que las fiestas hacen referencia a los misterios eleusinos. ${ }^{19}$ Esta hipóteis parece errada ya que los misterios tienen una fecha exacta en el calendario ateniense en la que se deben celebrar, Boedromion. Seguramente, la panegiris hace referencia a las Eleusinias, fiestas que se llevaban a cabo tras los misterios en el mes ático Pianopsion que precede al mes Memacterión. ${ }^{20}$ Sin embargo, aunque aparezcan las Eleusinias, éstas no habían sido consideradas por Adriano como auténticos juegos atléticos, sino que serían utilizadas por el Emperador como referencia cronológica a través del cual insertar los juegos Adrianeos. Las fuentes epigráficas sobre los agones dedicados a Adriano en Atenas aportan muy poca información de los mismos. Probablemente se fundaron en el 131/2 d.C., en conexión con una de las visitas del Emperador a la ciudad, ya que la primera mención que se hace de ellos en un palmarés atlético data de 140/1 d.C. ${ }^{21}$

En el calendario adrianeo aparecen otros agones atenienses dedicados al emperador, los juegos Olimpios: "(los atletas irán) a los concursos del Koinon de los Aqueos y Arcadios que se celebran en Mantinea, y después, los Olimpios ('O $\lambda u ́ \mu \pi \varepsilon 1 \alpha$ )". ${ }^{22}$ El nombre usado para designar estos concursos, 'O $\lambda \hat{\mu} \mu \pi \varepsilon 1 \alpha$, es característico de los juegos que se celebraban en Atenas. Como señala J.-Y. Strasser no pueden ser confundidos con los Olímpicos que se celebraban en el santuario de Olimpia ya que

\footnotetext{
Moretti $1953, \mathrm{n}^{\circ} 72$.

$I G \mathrm{II}^{2}, 2241$ y 2245 . Véase también: $I G \mathrm{II}^{2}, 2235$; OLIVER 1941a, 251, nº 53; SHEAR 2001,1082-1083.

Petzl - Schwertheim 2006, 11. 62-63. Traducción de Cortés Copete (e.p.).

Id. 1. 70. Traducción id.

Clinton 2008, 265; Le Guen 2010, 213; Strasser 2010, 610-611; RigSby 2010.

21 Follet 1976, 348-349; Graindor 1934, 43 y 210; Strasser 2010, 611. Sobre los juegos Adrianeos véase: $F D$ III.1, 89, 549 A-D, 550; FD III 4, 308; FD III 6, 143; IG II $^{2}, 1348,2042,2047,2049,2050,2052,2059,2065$, 2067, 2068, 2086, 2087, 2094, 2097, 2103, 2114, 2119, 2130, 2199, 2201,2235, 2237, 2239, 3015, 3163; IGR I, 153, 444; IGR IV, 160, 1432, 1519, 1761; IvEph 1112, 1131, 1613, 2072; TAM II, 587; KAPETANOPOULOS Malouchou 2010, n 3; Svoronos 1923-1926, pl. 91, 33. De forma general sobre los viajes de Adriano véase: Boatwright 2000; Weber 1907; Halfmann 1986; Syme 1988; Højte 2000; Birley 2004.

22 PetZl - SchWertheim 2006, 170.
} 
éstos son denominados ' $\mathrm{O} \lambda \hat{u} \mu \pi 1 \alpha .{ }^{23}$ Los agones atenienses se fundan en época adrianea con motivo de la conmemoración de la ayuda prestada por el Emperador en la culminación del Olimpeion ateniense: "En fait la fondation du concours ne peut être liée qu'à l'achèvement de l'Olympeion, en 128/9, ou à la statue de Zeus Olympios, en 131/2". ${ }^{24}$ Sobre estos juegos Olimpios hay cierta documentación epigráfica pero, a pesar de ella, no tenemos constancia del mes del año en el que se celebraban. Una primera hipótesis podría ser que los juegos se llevaran a cabo el 19 de Muniquión, mes en el que se celebraban los antiguos juegos Olimpios instaurados por Pisístrato en la ciudad. ${ }^{25}$ Sin embargo, no considero que los ciudadanos atenienses quisieran mantener una fecha que vinculaba los juegos con el pasado ático. Los juegos Olimpios del siglo VI a.C. honran a Pisístrato como planificador del templo del Olimpieion ateniense y su labor evergética para la ciudad de Atenas. Pero en el siglo II d.C. quien está beneficiando a Atenas y a quien se le ha honrado como Olimpios es el emperador Adriano. De este modo, es probable que la ciudad vinculase el momento en que deberían celebrarse los juegos Olimpios con el Emperador, su nuevo ktistes. Sin embargo, antes de ofrecer una hipótesis distinta sobre cuándo se celebraban los juegos Olimpios de Atenas, considero que es necesario analizar primero el último de los concursos atenienses que aparecen en el calendario de Adriano, los Panhelenos.

Los juegos Panhelenos aparecen dos veces en el calendario adrianeo, una de ellas asociada a los Olimpios de Atenas, donde se hace mención expresa a la celebración de ambos agones en el mismo año; “ “... y después, los Olimpios ('O $\lambda \dot{\mu} \mu \pi \varepsilon 1 \alpha)$. En este mismo año se celebrarán los Panhelenos". ${ }^{26}$ Por otra parte, en las líneas 63-64, se explicita que los Panhelenos eran los juegos que cerraban el circuito adrianeo ya que después se menciona los concursos Olímpicos de Olimpia que inician el nuevo

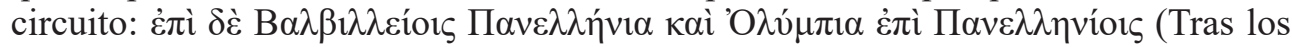
(juegos) Balbileos, los (juegos) Panhelenos y los (juegos) Olímpicos tras los (juegos) Panhelenos). ${ }^{27}$ Como su propio nombre indica, los juegos Panhelenos eran organizados por la asamblea del Panhelenion, fundada en la ciudad de Atenas en el 131/2 d.C. con el beneplácito del emperador Adriano. A través de un epígrafe hallado en la ciudad de Ezanos se puede fechar el año en que tuvo lugar la primera celebración de los juegos. En él aparece M. Ulpiu Euricles dedicando al emperador Adriano y a distintos dioses un puente erigido sobre el río Penkalas en el año en que tuvieron lugar los $234^{\circ}$ juegos Olimpicos y $6^{\circ}$ juegos Panhelenos. Al realizar la conversión con los juegos Olímpicos, M. Wörrle indica que la primera celebración de los juegos Panhelenos de Atenas debió de tener lugar en el 137 d.C, es decir, el cuarto año olímpico del calendario adrianeo. ${ }^{28}$ Aunque las fuentes no precisan el mes en el que se celebraban los concursos Panhelenos, a través del calendario adrianeo conocemos que debían ubicarse al final del cuarto año olímpico, entre los juegos Balbileos y el inicio del nuevo circuito con la celebración de los juegos Olímpicos (véase Fig 1). ${ }^{29}$

\footnotetext{
STRASSER 2010, 614-615.

Follet 1976, 346; ver también GRAINDOR 1934, 42.

Plu. Phoc. 37-I.

Petzl - Schwertheim 2006, 1. 70. Traducción de Cortés Copete (e.p.).

Id. 11. 63-64. Traducción id.

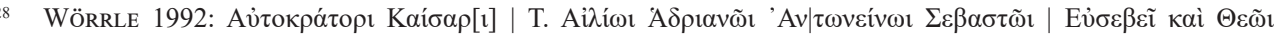

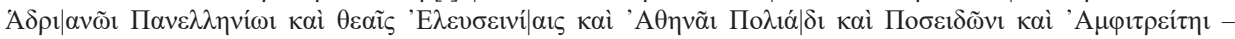

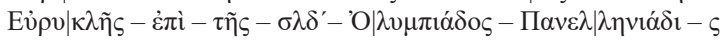

29 Sobre los juegos Balbileos véase: Boutet - LANOuEtTe 2007.
} 
La relación existente entre los juegos Panhelenos y Olimpios de Atenas, como se constata en el calendario adrianeo, puede ayudar a arrojar luz sobre el momento en el cual tenían lugar los Olimpios. De nuevo, las inscripciones relativas a los palmareses atléticos van a servir como argumentación principal para sugerir el momento en el cual se llevaban a cabo los juegos Olimpios. En la línea 25 de la inscripción de $\mathrm{M}$. Aurelio Asclepiades, pancratista circa 200 d.C., aparece el elenco de los juegos en

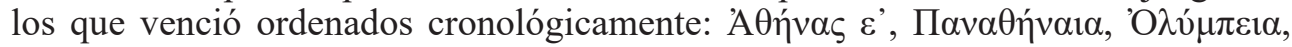
$\Pi \alpha v \varepsilon \lambda \lambda \eta ́ v i \alpha .{ }^{30}$ De este modo, los juegos Olimpios se desarrollarían en algún momento entre los Panateneos y los Panhelenos. En la inscripción de un pentatleta desconocido de Éfeso de la segunda mitad del siglo II d.C. el orden tras los juegos

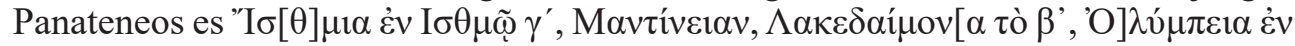
A $\theta$ ńvaıs. ${ }^{31}$ Por desgracia, la inscripción no indica el nombre de los juegos que el atleta ganó en Mantinea. Sin embargo, en el amplio palmarés de M. Aurelio Demóstrato

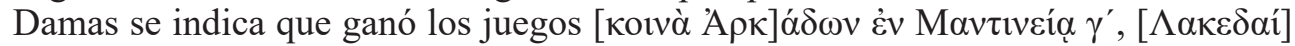
$\mu$ ov $\alpha \varsigma^{\prime} .^{32} \mathrm{Si}$ como indica la inscripción de Damas, los juegos que se realizaban antes de los Lacedemonios eran los juegos del Koinon de Arcadios en Mantinea, es probable que en la inscripción del atleta desconocido al indicar Mantinea, se haga referencia a estos juegos. En el calendario adrianeo, la correspondencia Istmia - Koinon de Mantinea- Olimpios de Atenas, está bien establecida por el Emperador. De este modo, si los juegos de Mantinea se pudieran ubicar tras la realización de los juegos de Istmia en el cuarto año olímpico, los juegos Olimpios habrían tenido lugar justamente tras los del Koinon de Arcadios, probablemente en torno al mes ático Posideón (véase Fig. 1). ${ }^{33}$

Una pregunta subyace en esta interpretación, si los nuevos juegos Olimpios atenienses se llevan a cabo en el mes Posideón. ¿Cuál es la asociación entre Adriano y este mes ático? La epigrafía documenta que en algún momento después del 124/5 d.C., se altera el nombre del mes intercalar ateniense, Posideón. El tradicional mes Posideón

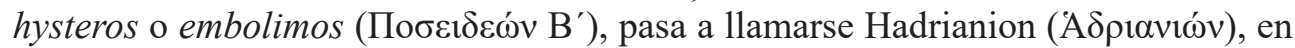
honor al Emperador. ${ }^{34}$ El cambio en la nomenclatura de los meses en los calendarios provinciales como "método para honrar" a los emperadores era una práctica común. En algunas ocasiones se tomaba el nombre propio del emperador, mientras que en

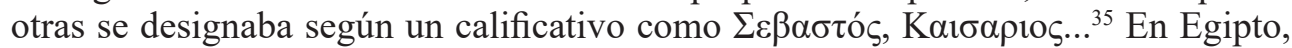
el mes Choiak (diciembre) fue renombrado como A $\delta \rho \imath \alpha$ ós, en honor al Emperador. La teoría tradicional indica que el cambio en la nomenclatura egipcia se realiza en torno al 130 d.C., para conmemorar el viaje de Adriano y su corte por Egipto. ${ }^{36}$ Sin embargo, los estudios de K. Scott sobre la epigrafía egipcia muestran que "the month

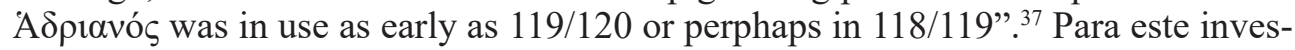
tigador la única conexión que justifica el cambio en la nomenclatura del mes Choiak es la conmemoración del 10 de diciembre del 117 d.C., día en el que el Emperador

\footnotetext{
IG XIV 1102; IGR I, 153; MORETTI 1953, $\mathrm{n}^{\circ} 79$

Id. $\mathrm{n}^{\mathrm{o}} 75$.

Id. $\mathrm{n}^{\circ} 84$.

Véase más adelante la explicación relativa a la inserción de los juegos Ístmicos en el cuarto año del circuito olímpico y no en el tercero, como era lo tradicional.

Follet 1976, 363; Scott 1931, 241.

SAMUEL 1972 .

Weber 1907, 257; Birley 1997, 252. Véase, por ejemplo, BARNS - ZilliaCus 1967, nº 187.

Sсотт 1931, 261.
} 
recibe su segunda tribunicia potestas. Aunque la conexión del mes Posideón con el emperador queda abierta al debate, es posible hipotetizar que los atenienses siguieran el ejemplo egipcio al usar el mes Posideón $=$ Choiak $=$ diciembre, para honrar al emperador Adriano. El cambio del nombre del mes intercalar y la celebración de los nuevos juegos Olimpios en Posideón podría reflejar la tradición oriental, iniciada por el mundo egipcio, de conmemorar la renovación de los poderes del emperador Adriano en Roma.

El emperador Adriano dirigió unas palabras a la ciudad ateniense donde resume el interés que manifestó en la rehabilitación de Atenas: ไ̌ $\sigma \tau \varepsilon \omega \varsigma \varsigma \pi \alpha ́ \sigma \alpha 1 \varsigma \chi \rho \tilde{\omega} \mu \alpha 1$

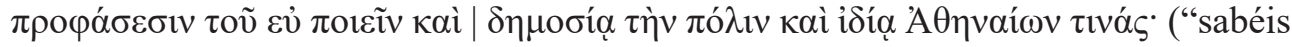
que aprovecho todas las ocasiones de favorecer tanto oficialmente a la ciudad como en particular a algunos atenienses"). ${ }^{38}$ El mundo agonístico también forma parte de su política de rehabilitación de la ciudad. Tres nuevos juegos se instalan en el calendario religioso, mientras que los juegos Panateneos suben de estatus al conseguir del Emperador la iselasis. Sin embargo, frente a esta reforma, en el calendario atlético el Emperador muestra su intención de mantener los juegos Panateneos en su posición tradicional, ya que ningún otro juego rivalizaba con ellos por la ubicación temporal, coinciendo con las celebraciones por el nacimiento de la diosa Atenea. De este modo, ante la inserción de los agones del circuito oriental, los únicos juegos que podrían haber sufrido un traslado en el calendario serían los juegos Píticos de Delfos.

\section{La ubicación temporal de los juegos Píticos en el calendario atlético adrianeo}

La segunda hipótesis pretende el cambio de los juegos Píticos desde el tercer al cuarto año olímpico, propuesta en primer lugar por los editores de las cartas de Alejandría en la Tróade, G. Petzl y E. Schwerteim, y seguida por L. J. Shear. Como bien indica L. J. Shear, es interesante que, en un calendario tan exhaustivo, el Emperador no indique los días de que disponen los atletas para ir desde de Éfeso hasta el santuario de Delfos, donde seguidamente se desarrollaban los juegos Píticos. Esta carencia es considerada por L. J. Shear como un indicio de la gran cantidad de días con que contaban los atletas para cruzar el Egeo, por lo que los juegos Píticos no se habrían de celebrar en el tercer año sino en el cuarto año olímpico. ${ }^{39}$

El problema que ven los investigadores en la elaboración del calendario atlético adrianeo, es que los juegos Píticos parecen competir por la ubicuidad temporal con los tres grandes juegos organizados por el Koinon de Asia (Esmirna, Pérgamo y Éfeso), ya que todos ellos podrían haberse celebrado durante el verano del tercer año olímpico, como sugieren los palmareses atléticos. En el caso de Heras de Quíos, los juegos del Koinon de Asia en Esmirna, Éfeso y Pérgamo aparecen entre los juegos del circuito itálico (Capitolinos, Sebastos y Actiacos) y los juegos Ístmicos. El circuito itálico se desarrollaba durante el segundo año olímpico, mientras que los juegos Ístmicos se llevaban a cabo en el tercer año olímpico (véase Fig. 1). Sin embargo, en el ya citado palmarés de Elio Aristómaco ${ }^{40}$ tras los juegos del circuito itálico se encuentran los Panateneos seguidos de los del Koinon de Asia en Esmirna

$I G \mathrm{II}^{2} 1102$, 11. 10-11. Traducción de CoRTÉs COPETE (e.p.).

SHEAR 2012, 164-165.

40 Véase supra, apartado: La ubicación temporal de los juegos Panateneos en el calendario atlético adrianeo. 
y los Ístmicos, sin que se haga mención explícita a los juegos Píticos. Como se ha comentado anteriormente, los juegos Panateneos se organizaban en el tercer año olímpico, al igual que, como se verá más adelante, los juegos Ístmicos. Por lo tanto, los juegos del Koinon asiático deberían celebrarse tras los juegos Panateneos en el tercer año olímpico. ${ }^{41}$ Teniendo en cuenta esta hipótesis, la ausencia de los juegos Píticos en los palmareses de los atletas citados podría indicar que los atletas habían dedicido participar en los concursos asiáticos renunciando a los agones Píticos. En caso de optar por los juegos de Delfos, los participantes tan sólo podían conseguir coronarse en un juego iselástico, los Píticos. La elección de los juegos organizados por el Koinon de Asia podría resultar más atrayente, ya que los atletas y technitai podían rentabilizar el viaje y competir en los tres grandes juegos del "circuito asiático" consecutivamente, Esmirna, Éfeso y Pérgamo.

Bajo dominación romana, los juegos Píticos seguían bajo el control de la Anfictionía de Delfos, una liga de ciudades griegas de carácter político-religioso. ${ }^{42}$ Cuando el emperador Adriano llegó al poder, el consejo anfictiónico mantenía la distribución impuesta por el emperador Nerón: 4 consejeros de Nicópolis, 12 de Tesalia, 12 de Focea, 2 de Delfos, 2 dorios, 2 jonios, 2 beocios y 2 locrios. Los hallazgos epigráficos muestran que la región de Tesalia tenía gran protagonismo en el consejo y en la organización de los juegos Píticos. De los ocho epimeletas, quienes se encargaban entre otras cosas de organizar los juegos Píticos, atestiguados desde la caída del Nerón hasta el gobierno de Adriano, uno proviene de la ciudad de Delfos, otro es beocio, y los restantes seis son oriundos de Tesalia. El emperador Adriano intentó intervenir en el consejo de la Anfictionía y reorganizar el sistema de votos de manera que fuera un poco más homogéneo. Las epístolas halladas en el santuario pítico muestran el interés del Emperador por disminuir el protagonismo de Tesalia y aumentar entre otros el

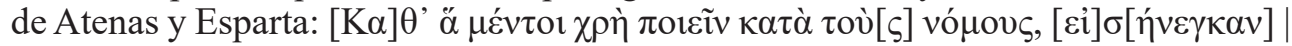

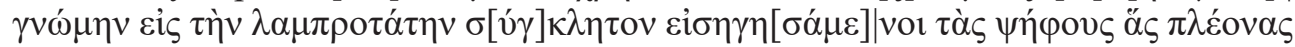

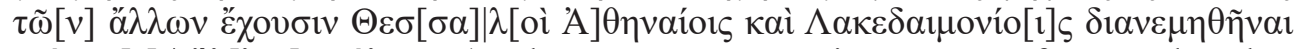

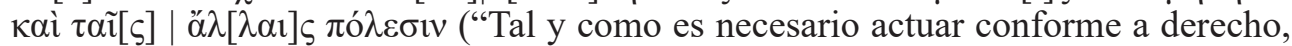
han presentado el proyecto ante el ilustrísimo senado, habiendo propuesto que los votos con los que los tesalios superan a los demás se repartan entre los atenienses, lacedemonios y las demás ciudades"). ${ }^{43}$ Reformas que finalmente nunca llegaron

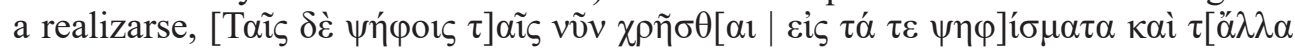

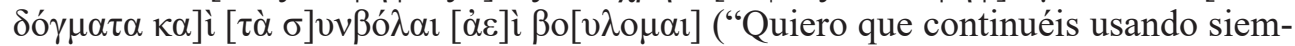
pre el actual reparto de votos tanto para los decretos como para las demás decisiones y contratos"). ${ }^{44}$

El protagonismo de Tesalia en la Anfictionía podría ser un reflejo del declive que presentan los juegos Píticos en época adrianea. La Anfictionía de Delfos tenía dos centros de culto: Delfos, en torno al templo de Apolo, y Pilea, en torno al templo de Deméter, más cercano a Tesalia. Según indica J. M. Cortés Copete, al menos en época adrianea los juegos Píticos se habían doblado y se celebraban en ambas sedes de la Anfictionía: primero en Delfos y a continuación en Pilea. ${ }^{45}$ Los epígrafes que

41 CAldelli 1993, no 28 ; STRASSER 2000, nº 50a y 347.

42 Sobre la Anfictionía de forma general véase: DAux 1976; PouIlloux 1980; Lefèvre 1998; SÁNCHEZ 2001; WEIR 2004.

43 FD III.IV, 302, Col. II, 11. 1-5. Traducción de CoRTÉs COPETE 1999, 96.

$44 \quad F D$ III.IV, 302, Col. II, 11. 16-18. Traducción id. 98.

45 Traducción id. 100. 
hacen referencia a las cartas del emperador Adriano a la ciudad de Delfos indican que los tesalios comenzaron a promover el santuario de Pilea en perjuicio de la sede de Delfos, traspasando el protagonismo que tenían los juegos Píticos de Delfos hacia los juegos de Pilea. Para ello, los tesalios otorgaban coronas de vencedor pítico a los ganadores de unos juegos que sólo se celebraban en el santuario de Pilea, dejando a los juegos píticos en un segundo plano. Ante tal abuso, el emperador Adriano dispu-

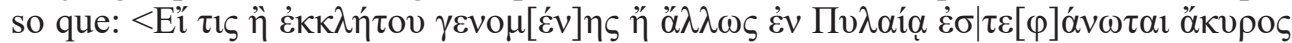
ó $\alpha \gamma \omega ̀ v ~ \varepsilon ̌ \sigma \tau \omega \kappa \alpha[i] \tau \tilde{~} v \varepsilon 1 \kappa \eta ́ \sigma \alpha v \tau \imath ~ \lambda \varepsilon \lambda \hat{\sigma} \sigma \theta \omega \mid \dot{\eta}[v] \varepsilon i ́ \kappa \eta$ ("Si alguno ha recibido una corona en Pilea, haya habido convocatoria o de alguna otra manera, que la competición sea declarada nula y que al vencedor se le prive de su victoria"). ${ }^{46}$ Sin embargo, si el vencedor hubiera competido, según la tradición, tanto en Delfos como en Pilea,

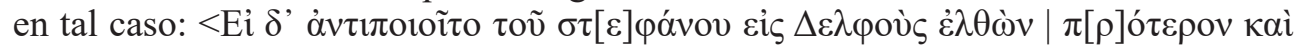

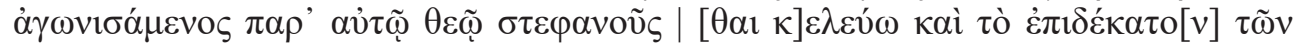

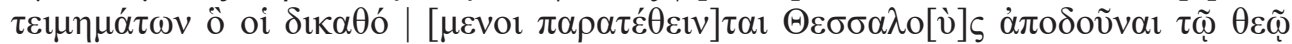
("Pero si alguien reclamase la corona porque primero fue a Delfos y compitió ante el propio dios, ordeno que sea coronado y que los tesalios entreguen al dios el diezmo de las fianzas que los litigantes ofrecieron"). ${ }^{47}$

Las cartas del emperador Adriano a la ciudad de Delfos muestran que los juegos Píticos habían perdido parte del esplendor que tenían desde época clásica. La duplicidad de los juegos de Delfos en dos sedes indica que los juegos dependían totalmente del interés que los miembros de la Anfictionía proyectasen sobre el santuario de Delfos. J. M. Cortés Copete sugiere que los juegos se duplicaron ante la inserción del culto imperial y la necesidad de dotar a los juegos de Pilea de un sustento organizativo. Sin embargo, en época adrianea, el abuso de los tesalios se hace evidente. El protagonismo en cuanto a número de consejeros y la impotencia con la que se encuentra el Emperador ante la reforma del consejo, dejan a los tesalios vía libre para imponer sus proyectos. De este modo, los juegos Píticos pierden su protagonismo ante las competiciones que se están llevando a cabo en el santuario de Pilea, ya que para ser coronado vencedor de los juegos Píticos los atletas tan sólo necesitaban competir en uno de los dos juegos, o en Pilea o en Delfos.

Ante la perspectiva délfica, se podría suponer que en el momento de elaboración del calendario atlético, el Emperador favorece a los juegos del Koinon de Asia frente a los juegos Píticos. De este modo, en el calendario adrianeo, el Emperador opta por otorgar a los juegos del Koinon su espacio en el tercer año olímpico, cambiando la celebración de los Píticos al cuarto año olímpico (véase Fig. 1). Desde una perspectiva religiosa, la reubicación de los juegos Píticos no presentaría ningún problema, ya que seguirán llevándose a cabo, como hasta ahora, en el mes délfico Bucatio. Por otro lado, en el plano atlético, este cambio hace que se reserve un espacio de tiempo en el calendario olímpico dedicado sólo y exclusivamente a los juegos Píticos, de modo que, como pasaba antes de la reorganización adrianea, no tengan que rivalizar con otros agones. Sin embargo, el cambio de los juegos Píticos está evidenciando el problema principal al que se enfrentan los juegos de Delfos, esto es, la pérdida de prestigio ante los ojos del Emperador, debido principalmente a los problemas surgidos por la organización de los miembros en la Anfictionía délfica.

FD III.IV, 302, Col. II. 11. 6-8. Traducción id. 100.

Id. 11. 8-11. Traducción id. 100. 


\section{Consecuencias de la reubicación de los agones Píticos: los juegos Ístmicos}

En la segunda mención de los juegos Ístmicos en el calendario adrianeo se hace referencia a la relación de los juegos Píticos y los Ístmicos. En la línea 70 el Emperador

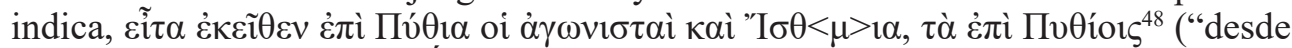
allí irán a los Píticos y los Ístmicos, aquellos que se celebran tras los Píticos"). Siguiendo la hipótesis anteriormente comentada, si los Píticos cambian su ubicación desde el tercer al cuarto año olímpico, los Ístmicos, al estar asociados, también deberían trasladarse al cuarto año olímpico.

En época clásica los juegos Ístmicos de Corinto se realizaban en la primavera del primer año olímpico, precediendo la celebración de los juegos Olímpicos de Olimpia, y del tercer año olímpico, precediendo, en este caso, a los Píticos de Delfos. En la segunda carta de la estela de Alejandría en la Tróade los juegos Ístmicos aparecen mencionados en dos ocasiones. En la primera de ellas se establece que los Ístmicos se celebran durante el primer año olímpico. El Emperador usa el imperativo indican-

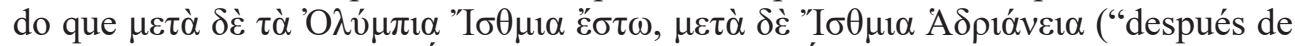
los Olímpicos vendrán los Ístmicos, y detrás de los Ístmicos, los Adrianeos"). ${ }^{49}$ Los editores de las cartas analizan el uso del modo imperativo por el Emperador como indicativo de algún cambio que está llevando a cabo en la organización agonística, ${ }^{50}$ esto es, el aplazamiento de la realización de los juegos Ístmicos tras los juegos Olímpicos, a final de verano del primer año olímpico. Aunque significativa, ${ }^{51}$ esta alteración seguramente podría quedar justificada por el complejo encaje de fiestas que el Emperador realiza para evitar la superposición de dos o más competiciones, de manera que todas tengan reservado un periodo de tiempo fijo en uno de los cuatro años olímpicos. Si observamos el final del calendario adrianeo referente al cuarto año olímpico, se advierte que, antes de la celebración de los nuevos juegos Olímpicos, en Atenas se debían realizar los juegos Olimpios y los Panhelenos tras los juegos Olimpios y Balbileos de Éfeso (véase Fig. 1). Siguiendo este esquema, es indudable que el Emperador tenía dos opciones: o mantener la posición tradicional de los juegos Ístmicos o priorizar los juegos Panhelenos que, aunque su primera celebración se fecha en el año 137 d.C., eran de gran importancia para el Emperador ya que celebraban su divinidad como Adriano Panhelenio y el nacimiento de la liga del Panhellenion.

Por otro lado, en la línea 70 del calendario adrianeo hay un nuevo cambio de posición, ya que anteceden a los juegos Olímpicos. Es decir, en el nuevo calendario adrianeo, los juegos Ístmicos pasan de celebrarse en primavera, antes de los juegos Píticos según el calendario tradicional, para estar ubicados a final de verano, tras la finalización de los juegos Píticos. Según J. L. Shear, este cambio podría haber sido impulsado por el emperador Adriano con anterioridad a su organización del calendario atlético. En el citado palmarés de Elio Aristómaco las competiciones se organizan de la siguiente manera: Olímpicos, Capitolinos, Sebastos, Actíacos, Panateneos,

\footnotetext{
SEG 56, 1359, 1. 70.

Id. 1.62 .

Petzl - Schwertheim 2006, 72. Traducción de Cortés Copete (e.p.).

STRASSER 2010, 610; el cambio que Adriano lleva a cabo en el primer año olímpico, retrasando los juegos Ístmicos hasta la culminación de los Olímpicos, no reviste importancia ya que, según este investigador, desde la destrucción de Corinto y la vuelta de los juegos a la ciudad diversos cambios podrían haber acaecido en la organización de los juegos.
} 
Koinon de Asia en Esmirna, Ístmicos, Nemeos, Uranios de Lacedemonia e Ístmicos de nuevo ${ }^{52}$. Si, como se ha comentado anteriormente, los juegos Píticos y los del Koinon de Asia en Esmirna se están celebrando en el mismo año olímpico y en el mismo periodo de tiempo, es normal que sólo uno de los dos aparezca en la inscripción, ya que el atleta sólo podría competir en uno de ellos. Igualmente, el hecho de que los juegos Î́stmicos sí aparezcan en la inscripción podría ser un indicio de que en este momento se están celebrando después de los Píticos/Koinon de Asia esmirneo y no antes como era lo tradicional. J. L. Shear fecha el cambio de los juegos Ístmicos en el 119 d.C. atendiendo a las categorías de edad en las que Elio Aristómaco pudo haber ganado los juegos de Olimpia y las Panateneas. ${ }^{53} \mathrm{El}$ ordenamiento agonístico que deriva de esta interpretación es un claro ejemplo del problema al que se enfrentaban los atletas y technitai, ya que había muchas fiestas que se superponían en el tiempo, y de la necesidad de la reorganización agonística propiciada por el Emperador. Sin embargo, una pregunta subyace de esta interpretación, ¿por qué los juegos Ístmicos cambian en relación con los Píticos? ¿Hay alguna fiesta que pudiera competir en el tiempo con los Ístmicos tradicionales?

Como se ha comentado anteriormente, el problema principal que se encuentra el Emperador es la adecuación temporal de los juegos Panateneos, los del Koinon de Asia en Esmirna y los Píticos. Sin embargo, no parece que haya problema en el hecho de que los Ístmicos se realicen antes de los Píticos. Si se observa la figura 1 anexa al final del artículo, las columnas relativas a la interpretación de los primeros editores de las cartas y la de J. L. Shear, de los juegos que se celebran en la primavera del segundo año olímpico, se observa que no hay ninguna competición anterior a los juegos Panateneos que pueda quitarle el espacio a los Ístmicos. Por otro lado, las interpretaciones de W. J. Slater, J. Y. Strasser y P. Gouw, insertan los Panateneos en la primavera del segundo año olímpico por lo que los juegos Adrianeos de Éfeso podrían ser un impedimento para la celebración de los juegos Ístmicos y por lo tanto ser la causa de su cambio temporal.

Los juegos Adrianeos de Éfeso son uno de los agones mejor conocidos debido a la cantidad de testimonios que se han conservado. ${ }^{54}$ La epigrafía y la numismática han permitido reconstruir las competiciones que formaban parte de las fiestas, así como el nombre de los agonotetas encargados de su organización. ${ }^{55}$ A pesar de ello, hay una cuestión que sigue siendo objeto de debate científico: el año en que tuvo lugar la primera celebración. La hipótesis tradicional de M. Lämmer, indica que se organizan por primera vez en el 124 d.C., coinciendo con una de las visitas

\footnotetext{
Véase lo dicho supra.

SHEAR 2012, 160 y 168.

54 IG III, 129, 370; IG XIV, 739, 1102, 1113; IGR IV, 1432; FD III.1, 550IvO 237; IvEph 618, 724, 730, 1085a, 1087a, 1153, 1083, 1132, 1604, 2072, 4114; CIL III, 296; SEG 40, 1141; SEG 14,735; SEG 36, 258; SEG 43, 731; CIG IV, 1645, 5913; Caldelli 1993, nº 28; Bey 1904, nº 7; Roueché 1993, nº 67; MoretTi 1953, nº 86; Bloesch 1997, 2950. Sobre los juegos dedicados a Adriano véase de forma general: Lämmer 1967; Le GLAY 1976; LESCHHOR 1998, n. 10; BOATWRIGHT 2000, 99-101.

55 Las inscripciones denominan los juegos dedicados al culto de Adriano en Éfeso de cuatro maneras diferentes: Adrianeia, Megala Adrianeia, Adrianeia Olimpia y posteriormente Adrianeia Comodeia. Contaban con juegos divididos en tres categorías de edad: paides, ageneioi y andres. Las pruebas seguían la tradición agonística al contar con ejercicios musicales y atléticas. Las inscripciones nos revelan los nombres de algunos cargos encargados de la organización de los juegos. Entre los agonotetas aparece Aristócrates de Céramo, M. Fulvio Publicano y M. Antonio Loliano, algunos de ellos con el cargo en perpetuidad como Cn. Dottio o P. Vedio Papiano Antonino. Véase: LÄMMER 1967, 53-55.
} 
del Emperador a la ciudad de Éfeso. ${ }^{56}$ En contra de esta datación se encuentra J.-Y. Strasser, quien data la primera celebración en el 135 d.C. a través de la inscripción de Marco Ulpio Aristócrates, hijo de Hierocles, agonoteta de la segunda penteteria de los juegos Adrianeos de Éfeso. ${ }^{57}$ Según mi propio análisis de las fuentes, publicado recientemente en un artículo, la realización de los juegos habría que remontarla al 131 d.C. coincidiendo con la concesión de la segunda neokoría a la ciudad efesia. ${ }^{58}$

Si mantenemos la hipótesis planteada por J. L. Shear al datar en el 119 d.C. el cambio de emplazamiento de los juegos Ístmicos con respecto a los Píticos, los Adrianeos de Éfeso no podrían ser la causa de esta alteración en el calendario agonístico, ya que según las hipótesis anteriormente planteadas, su primera celebración es posterior: 124, 131, 133 o 135 d.C. Entonces, ¿por qué el cambio? Para poder encontrar una solución a este interrogante, primero hay que entender las consecuencias que tiene en la organización del calendario adrianeo la relación de los juegos Píticos con los Ístmicos.

Mantener la celebración de los juegos Píticos e Ístmicos en el cuarto año olímpico del calendario adrianeo conlleva un problema sobre la periodicidad de los Ístmicos que no ha sido solventada por los investigadores. Tradicionalmente, los juegos Ístmicos eran trietéricos o bienales, es decir, se celebraban cada dos años, en el primer y tercer año olímpico. Seguramente en época imperial los juegos seguían celebrándose con la misma periodicidad. ${ }^{59}$ Como se ha comentado, en el calendario adrianeo los Ístmicos se siguen llevando a cabo en el primer año en relación con los Olímpicos. Sin embargo, al cambiar los Píticos del tercer al cuarto año, los Ístmicos también deberían sufrir esta alteración y pasarían a celebrarse en el cuarto año olímpico. El problema del nuevo ciclo Ístmico que aparece reflejado en el calendario adrianeo radica en que los juegos se llevan a cabo en una secuencia temporal irregular, ya que se están celebrando en un ritmo de 3 años -1 año -3 años -1 año, en vez de seguir con su ciclo normal de 2 años. Es decir, según el calendario adrianeo, los juegos se habrían llevado a cabo en el 133, 136, 137, 140, 141 d.C., y así sucesivamente. Esta forma de secuenciar los juegos es una excepción ya que, tradicionalmente, todos los juegos llevan aparejada una cadencia temporal única de dos o cuatro años (juegos trietéricos o pentetéricos).

Una posible solución a este problema se encuentra en el propio calendario adrianeo. La primera vez que se hace mención de los Ístmicos es en la línea 62: $\mu \varepsilon \tau \hat{\alpha} \delta \dot{\varepsilon}$

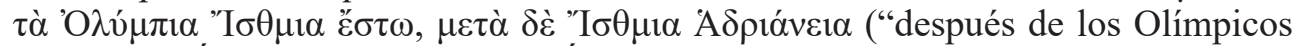
vendrán los Ístmicos, y detrás de los Ístmicos, los Adrianeos”), y la segunda vez en la

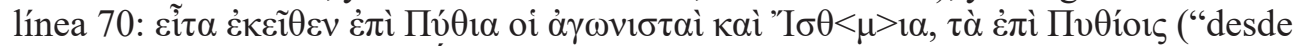
allí irán a los Píticos y los Ístmicos, aquellos que se celebran tras los Píticos"). La forma de nombrar los juegos en ambos pasajes de la carta es significativa. En la línea 62 aparecen tan sólo como "(juegos) Ístmicos" que se celebraban entre los Olímpicos y los Adrianeos de Atenas. Estos juegos son, seguramente, agones dedicados a Poseidón que, de manera tradicional, se llevaban a cabo en el santuario de Istmia y formaban parte de la archaia periodos.

\footnotetext{
Id. 40. Esta teoría ha sido seguida por MAGIE 1950, 619; LeHNER 2004, 198-199.

IvE 618 = CIG 2987b; Weber 1907, 214; Oliver 1941b, nº 9; CAMPanile 1994, 110-111, $\mathrm{n}^{\circ} 111$.

Burrell 2004, 67; Gordillo (e.p.).

Aristid. Or. 46.23 y 31.
} 
Sin embargo, en la línea 70, Adriano se refiere a los juegos Ístmicos calificándolos como "aquellos que se celebran tras los Píticos". El Emperador bien podría haber nombrado en la línea 70 a los juegos Ístmicos con el mismo término que utiliza en la línea 62, siempre que hubiesen sido los mismos. Es decir, si los juegos Ístmicos de la línea 62 son los mismos juegos que aparecen en la línea 70, ¿por qué el Emperador se toma el interés de calificar los Ístmicos de la línea 70 de una forma tan precisa? La hipótesis que se plantea en este estudio es que el emperador Adriano podría estar identificando en el calendario adrianeo dos juegos distintos que estarían intrínsecamente relacionados con el santuario de Istmia.

Los juegos Ístmicos, dedicados al dios Poseidón, se celebran en el santuario de Istmia desde el siglo VI a.C. En el año 146 a.C. el general Mummio saquea la ciudad de Corinto y destruye parte del santuario ístmico por lo que los juegos pasarán a ser administrados por la ciudad vecina de Sición. La arqueología y las fuentes epigráficas han permitido datar la vuelta de los juegos a la ciudad de Corinto en el siglo I a.C. ${ }^{60}$ mientras que su retorno al santuario ístmico no se llevaría a cabo hasta el siglo I d.C. ${ }^{61}$

Poco después de la batalla de Accio, probablemente en el año 30 a.C., la ciudad de Corinto organiza unos juegos de carácter pentetérico, que seguramente conmemoraban la victoria de Augusto frente a Marco Antonio y Cleopatra: los Cesareos. ${ }^{62} \mathrm{La}$ primera mención de los concursos aparece en una inscripción hallada en las inmediaciones del gimnasio de Corinto, donde se registra el nombre de los ganadores de

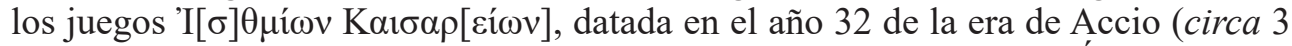
d.C.). ${ }^{63}$ En ella se puede observar la relación existente entre los juegos Ístmicos y los juegos Cesareos que, aunque de forma separada, es probable que se llevaran a cabo en el mismo año olímpico. Según el año en que ambos agones se organizarían por primera vez bajo el control de Corinto, es probable hipotetizar que los Cesareos se estuvieran celebrando antes de la vuelta de los Ístmicos a Corinto. ${ }^{64}$ Con la llegada de los Ístmicos, parece que los Cesareos se relacionan con los juegos precedentes, llevándose a cabo cada cuatro años. La documentación principal de la relación entre los juegos Ístmicos y Cesareos la encontramos en las inscripciones honoríficas

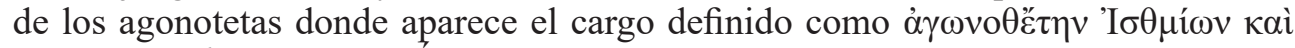
Kaı $\alpha \rho \eta ́ \omega v .{ }^{65}$ Los juegos İstmicos parecen quitar el protagonismo a los Cesareos. Esta podría ser la explicación de que en una inscripción datada en el año 35 d.C., Tito Manlio Juvenco, siendo agonoteta de los juegos Ístmicos y Cesareos, recordara el hecho de que él fue el primero en organizar los Cesareos antes de los Ístmicos. ${ }^{66}$

Los juegos Cesareos probablemente se celebrarían en septiembre, en conmemoración de la victoria de Accio. J.-Y. Strasser supone, según la datación de los palmareses atléticos, que se celebraban durante el tercer año olímpico. Este hecho sostendría la idea de que en el mismo año se llevarían a cabo tanto los juegos Cesareos como los Píticos. Si, como se ha comentado anteriormente, los Píticos se desarrollaban en

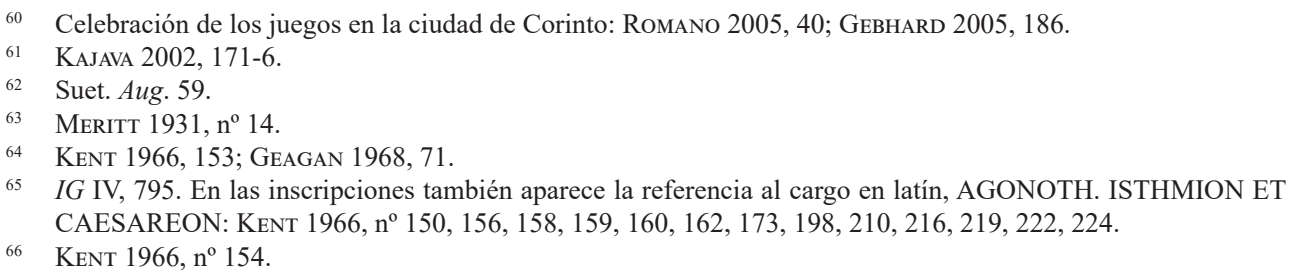


verano, es evidente que los Cesareos se organizarían justo después de los agones de Delfos. ${ }^{67}$ Teniendo en cuenta este argumento, se podría deducir que los juegos a los que el emperador Adriano hace referencia en la línea 70 de la segunda carta de la estela de Alejandría en la Tróade, no son los Ístmicos trietéricos sino la combinación de juegos Ístmicos y Cesareos de carácter pentetérico. El emperador Adriano, al cambiar los juegos Píticos del tercer al cuarto año, mueve los juegos ÍstmicosCesareos también al cuarto año. Sin embargo, este hecho no altera la periodicidad regular de los juegos Ístmicos, porque la relación Ístmicos-Cesareos se lleva a cabo en una cadencia de cuatro años. En este caso, Adriano mantiene la tradición festiva impuesta por el calendario corintio y olímpico. Así, en el calendario festivo corintio los juegos Ístmicos están íntimamente relacionados con los juegos Cesareos y en el calendario olímpico los juegos Cesareos, a su vez, dependen de los juegos Píticos.

Por ello, considero que para entender la implicación de los juegos Ístmicos en el calendario de Adriano hay que verlo de dos maneras distintas atendiendo a la relación de los juegos Ístmicos con los agones adyacentes. En el caso de los juegos Ístmicos que se desarrollan en el primer año, son los que J. H. Kent denomina como "Pequeños", es decir, los tradicionales que desde el siglo VI a.C. se han venido organizando cada dos años en Corinto o, temporalmente, en Sición. Sin embargo, los que se desarrollan en el cuarto año son los “Grandes", esto es, la conjunción de juegos Ístmicos y juegos Cesareos que se realizan cada cinco años. El emperador Adriano, al calificar a los concursos Ístmicos en la línea 70 como "aquellos que se celebran tras los Píticos", hace una diferenciación entre los dos tipos de agones Ístmicos.

Practicamente la totalidad de las inscripciones en las que se cita la agonotesía de un ciudadano en estos juegos, las fiestas Ístmicas suelen preceder a las Cesareas. Sin embargo, en época adrianea, se enfatiza la vinculación del agon con el culto imperial al invertir el orden y colocar en primer lugar los juegos Cesareos y en un segundo los Ístmicos. En dos inscripciones fechadas en época de Adriano se hace referencia al cursus honorum de Cn. Cornelio Pulcro. Entre los diferentes cargos que aparecen re-

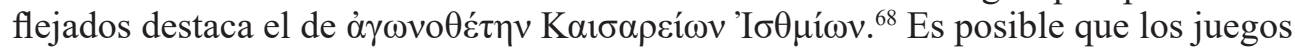
se llevaran a cabo en este orden, ya que en la inscripción anteriormente comentada de Tito Manlio Juvenco, se le honra, entre otras cosas, como el primero que celebra los juegos Cesareos antes que los Ístmicos. Sin embargo, tanto el propio Tito Manlio Juvenco como los restantes agonotetas de los que se tiene constancia siguen definiendo su agonotesía como Ístmica y Cesarea, sin tener en cuenta el orden temporal en el que se seguramente se venían desarrollando las celebraciones. Igualmente, cuando el Emperador menciona en la línea 70 los juegos, los llama Ístmicos y no Cesareos, debido probablemente a la nomenclatura por la que son conocidos entre los atletas y technitai. El cambio de nomenclatura puede responder al interés de la ciudadanía corintia de acercarse a la figura del Emperador a través de la vinculación manifiesta de los juegos con el culto imperial; en el caso de Cn. Cornelio Pulcro, entre muchas de sus atribuciones había sido arconte de la liga del Panhellenion, vinculada entre otras cosas, al culto del emperador Adriano. ${ }^{69}$

STRASSER 2010, 424.

68 IG IV, 1600; MeritT 1931, nº 80 y 81; Oliver 1970, nº 35; Kent 1966, nº 214, sin datación: [Caesa]reon et | [Is]thmion AG[---]S.

69 SPAWFORTH - WALKER 1985, 86. 


\section{Conclusiones}

La hipótesis de P. Gouw sobre el trasvase de los juegos Panateneos a la primavera del tercer año olímpico lleva aparejada una serie de problemas. En primer lugar destaca el problema religioso. Las fiestas consagradas a las divinidades debían realizarse en las fechas vinculadas con las divinidades afectadas. Si los juegos Panateneos conmemoran el nacimiento de la diosa, es decir, el 28 de Hecatombeón, el supuesto traslado de las fiestas desde este mes a la primavera del mismo año, habría indicado un desinterés de la ciudad por la religión y las tradiciones religiosas. En segundo lugar, la única referencia a la reubicación de los juegos Panateneos aparece en una fuente literaria tardía del siglo IV d.C., por lo que es posible que el cambio se realizara después de la elaboración del calendario adrianeo. En tercer lugar, no considero que se pueda hablar de decadencia de los juegos Panateneos en época imperial. En las inscripciones, aunque escasas, siguen apareciendo los juegos Panateneos de manera más o menos homogénea. El emperador Adriano, al otorgar el título iselástico a los juegos, los eleva a la categoría internacional y los introduce en la nueva periodos adrianea.

Por consiguiente, considero que la estructura del calendario adrianeo más verosímil es aquella que había sido iniciada por los editores de las cartas de Alejandría en la Tróade, G. Petzl y E. Schwertheim, que proponían el cambio de los juegos Píticos desde el tercer al cuarto año olímpico. Este cambio estaría sustentado por la rivalidad entre los juegos Píticos y los juegos del Koinon de Asia en Esmirna, los cuales se celebraban en el mismo momento y en el mismo año olímpico. Entre ambos juegos, el emperador Adriano elige trasladar los juegos Píticos al cuarto año olímpico seguramente movido por la falta de control en la Anfictionía de Delfos. El único problema que subyace tras esta interpretación es el cambio de periodicidad de los juegos Ístmicos que, ante el cambio de los juegos Píticos, deben trasladarse junto con ellos al cuarto año olímpico. Ante esta dificultad se puede sugerir que los juegos Ístmicos a los que el Emperador relaciona con los juegos Píticos no son los juegos Ístmicos de caracter trietérico sino los Ístmicos Cesareos que se celebraban cada cuatro años. Si se mantiene esta hipótesis, la estructura del tercer y cuarto año del calendario adrianeo estaría totalmente clarificada. 
Figura 1. Propuestas sobre el calendario de juegos atléticos adrianeo ${ }^{70}$

\begin{tabular}{|c|c|c|c|c|c|c|}
\hline Mes & $\begin{array}{l}\text { PETZL - } \\
\text { SCHWERTHEIM } \\
228^{\text {th }} \text { Olimpiada }\end{array}$ & $\begin{array}{l}\text { SLATER } \\
227^{\text {th }} \\
\text { Olimpiada }\end{array}$ & STRASSER & GouW & $\begin{array}{l}\text { SHEAR } \\
228^{\text {th }} \\
\text { Olimpiada }\end{array}$ & $\begin{array}{l}\text { NUEVA } \\
\text { PROPUESTA } \\
228^{\text {th }} \\
\text { Olimpiada }\end{array}$ \\
\hline \multicolumn{6}{|c|}{$1^{\mathrm{o}}$ año Olímpico (133- 134 d.C.) } & \\
\hline Jul. & \multirow{3}{*}{ Olímpicos } & \multirow[b]{2}{*}{ Olímpicos } & \multirow[b]{2}{*}{ Olímpicos } & \multirow[b]{2}{*}{ Olímpicos } & \multirow[b]{2}{*}{ Olímpicos } & \multirow[b]{2}{*}{ Olímpicos } \\
\hline Ago. & & & & & & \\
\hline Sep. & & Ístmicos & Ístmicos & Ístmicos & Ístmicos & Ístmicos \\
\hline Oct. & $\begin{array}{l}\text { pp. Oct. } \\
\text { Misterios }\end{array}$ & $\begin{array}{l}\text { pp. Oct. } \\
\text { Panegyris } \\
\text { de Eleusis }\end{array}$ & $\begin{array}{l}\text { pp. Oct. } \\
\text { Eleusinios }\end{array}$ & $\begin{array}{l}\text { pp. Oct. } \\
\text { Eleusinios } \\
1 \\
\text { Memacterión }\end{array}$ & & \\
\hline Nov. & $\begin{array}{l}\text { Misterios } \\
\text { Eleusis } \\
1 \\
\text { Memacterión } \\
\text { Adrianeos } \\
\text { (Atenas) }\end{array}$ & $\begin{array}{l}\text { Panegyris } \\
\text { de Eleusis } \\
1 \\
\text { Memacterión } \\
\text { Adrianeos } \\
\text { (Atenas) }\end{array}$ & $\begin{array}{l}1 \\
\text { Memacterión } \\
\text { Adrianeos } \\
\text { (Atenas) }\end{array}$ & $\begin{array}{l}\text { Eleusinios } \\
1 \\
\text { Memacterión } \\
\text { Adrianeos } \\
\text { (Atenas) }\end{array}$ & $\begin{array}{l}1 \\
\text { Memacterión } \\
\text { Adrianeos } \\
\text { (Atenas) }\end{array}$ & $\begin{array}{l}1 \\
\text { Memacterión } \\
\text { Adrianeos, } \\
\text { (Atenas) }\end{array}$ \\
\hline \multicolumn{7}{|l|}{ Dic. } \\
\hline $\begin{array}{l}\text { Ene. } \\
\text { (134) }\end{array}$ & $\begin{array}{l}\text { Eleusinios } \\
\text { (Tarento) }\end{array}$ & $\begin{array}{l}\text { Juegos de } \\
\text { Tarento }\end{array}$ & $\begin{array}{l}\text { Juegos de } \\
\text { Tarento }\end{array}$ & $\begin{array}{l}\text { Eleusinios? } \\
\text { (Tarento) }\end{array}$ & $\begin{array}{l}\text { Juegos de } \\
\text { Tarento }\end{array}$ & $\begin{array}{l}\text { Juegos de } \\
\text { Tarento }\end{array}$ \\
\hline \multicolumn{7}{|l|}{ Feb. } \\
\hline \multicolumn{7}{|l|}{ Mar. } \\
\hline \multicolumn{7}{|l|}{ Abr. } \\
\hline May. & \multirow[b]{2}{*}{ Capitolinos } & \multirow[b]{2}{*}{ Capitolinos } & \multirow[b]{2}{*}{ Capitolinos } & \multirow[b]{2}{*}{ Capitolinos } & \multirow[b]{2}{*}{ Capitolinos } & \multirow[b]{2}{*}{ Capitolinos } \\
\hline Jun. & & & & & & \\
\hline
\end{tabular}

70 Petzl - Schwertheim 2006; Slater 2008, 619; Strasser 2010, 621; Gouw 2009, 91-92; Gouw 2008, 102; SHEAR 2012, 159-172. 


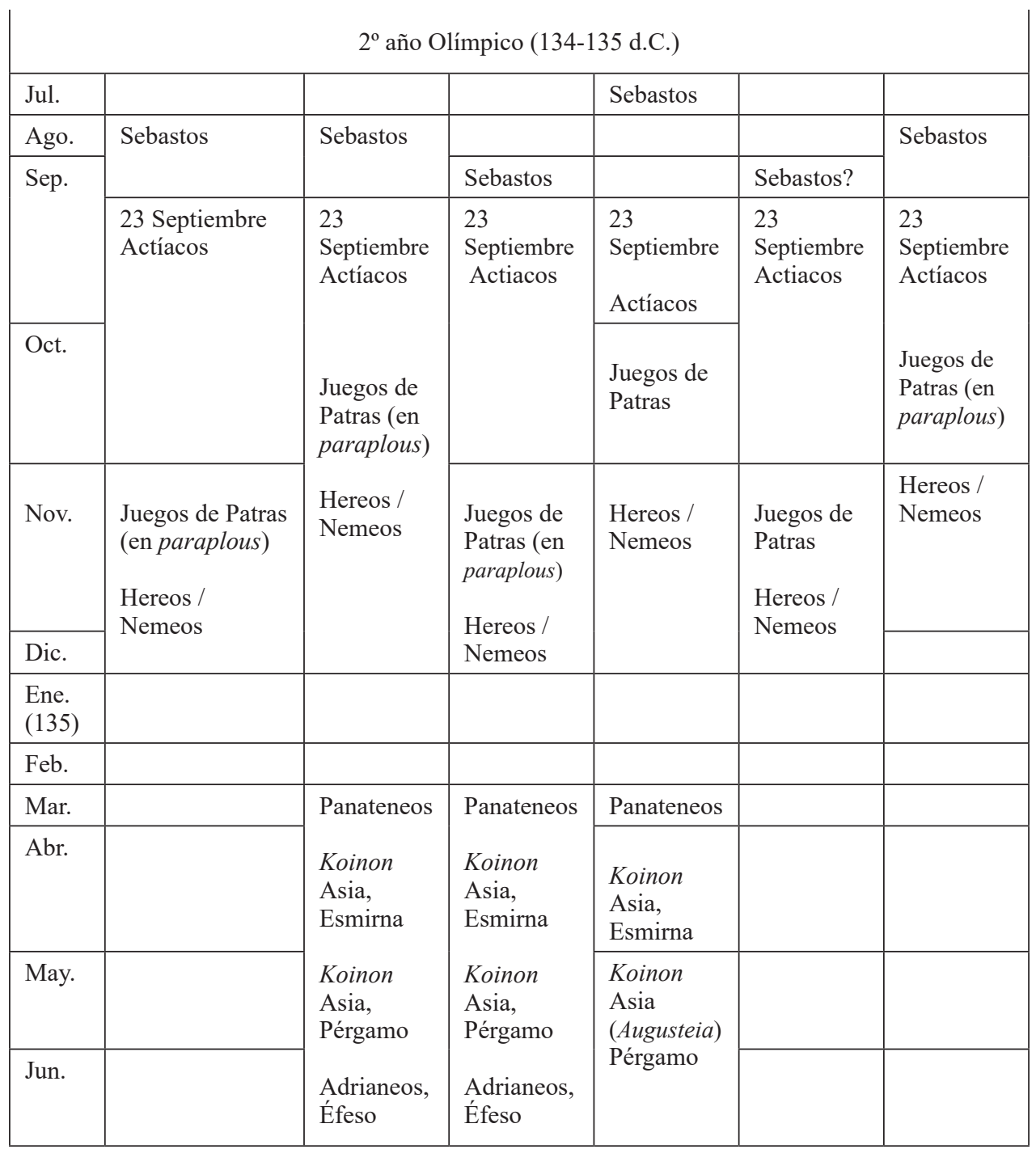




\begin{tabular}{|c|c|c|c|c|c|}
\hline \multicolumn{6}{|c|}{$3^{\circ}$ año Olímpico (135-136 d.C.) } \\
\hline Jul. & \multirow[b]{2}{*}{ Panateneos } & & $\begin{array}{l}\text { Adrianeos, } \\
\text { Éfeso }\end{array}$ & \multirow[b]{2}{*}{ Panateneos } & \multirow[b]{2}{*}{ Panateneos } \\
\hline Ago. & & & \multirow{2}{*}{ Píticos } & & \\
\hline Sep. & $\begin{array}{l}\text { Koinon Asia, } \\
\text { Esmirna }\end{array}$ & Píticos & & $\begin{array}{l}\text { Koinon } \\
\text { Asia, } \\
\text { Esmirna }\end{array}$ & $\begin{array}{l}\text { Koinon } \\
\text { Asia, } \\
\text { Esmirna }\end{array}$ \\
\hline Oct. & $\begin{array}{l}\text { Koinon Asia, } \\
\text { Pérgamo }\end{array}$ & Ístmicos & \multirow[t]{2}{*}{$\begin{array}{l}\text { Ístmicos } \\
\text { (Otoño) }\end{array}$} & $\begin{array}{l}\text { Koinon } \\
\text { Asia, } \\
\text { Pérgamo }\end{array}$ & $\begin{array}{l}\text { Koinon } \\
\text { Asia } \\
\text { Pérgamo }\end{array}$ \\
\hline \multicolumn{5}{|l|}{ Nov. } & \\
\hline Dic. & $\begin{array}{l}\text { Koinon Asia, } \\
\text { Éfeso }\end{array}$ & & & $\begin{array}{l}\text { Koinon Asia, } \\
\text { Éfeso }\end{array}$ & \multirow[t]{2}{*}{$\begin{array}{l}\text { Adrianeas? } \\
\text { Éfeso }\end{array}$} \\
\hline $\begin{array}{l}\text { Ene. } \\
(136)\end{array}$ & & \multirow{3}{*}{ Mantinea? } & & & \\
\hline Feb. & & & & & \\
\hline Mar. & & & & & \\
\hline Abr. & & \multirow[b]{2}{*}{$\begin{array}{l}\text { Olimpios, } \\
\text { Atenas }^{71}\end{array}$} & \multirow{2}{*}{ Mantinea } & & \\
\hline May. & & & & & \\
\hline Jun. & & & & & \\
\hline
\end{tabular}




\begin{tabular}{|c|c|c|c|c|c|c|}
\hline \multicolumn{7}{|c|}{$4^{\circ}$ año olímpico (136-137 d.C.) } \\
\hline Jul. & \multirow[b]{2}{*}{ Píticos } & \multirow[b]{2}{*}{ Píticos } & & & \multirow[b]{2}{*}{ Píticos } & \multirow[b]{2}{*}{ Píticos } \\
\hline Ago. & & & & & & \\
\hline Sep. & Ístmicos & Ístmicos & & & Ístmicos & $\begin{array}{l}\text { Cesareos } \\
\text { Ístmicos }\end{array}$ \\
\hline Oct. & & & & & & Mantinea \\
\hline Nov. & & & & & & \multirow{2}{*}{$\begin{array}{l}\text { Olimpios } \\
\text { (Atenas) }\end{array}$} \\
\hline Dic. & & & & & & \\
\hline $\begin{array}{l}\text { Ene. } \\
\text { (137) }\end{array}$ & $\begin{array}{l}\text { Mantinea } \\
\text { Alternativa: } \\
\text { día } 4 \\
\text { Adrianeos } \\
\text { Esmirna }\end{array}$ & $\begin{array}{l}\text { Mantinea } \\
\text { Alternativa: } \\
\text { día } 4 \\
\text { Adrianeos } \\
\text { Esmirna }\end{array}$ & $\begin{array}{l}\text { Adrianeos } \\
\text { Esmirna }\end{array}$ & $\begin{array}{l}\text { Adrianeos } \\
\text { Esmirna }\end{array}$ & $\begin{array}{l}\text { Mantinea } \\
\text { Alternativa: } \\
\text { día } 4 \\
\text { Adrianeos } \\
\text { Esmirna }\end{array}$ & $\begin{array}{l}\text { Adrianeos } \\
\text { Esmirna }\end{array}$ \\
\hline Feb. & $\begin{array}{l}\text { Olimpios, } \\
\text { Éfeso }\end{array}$ & $\begin{array}{l}\text { Olimpios, } \\
\text { Éfeso }\end{array}$ & & $\begin{array}{l}\text { Olimpios, } \\
\text { Éfeso }\end{array}$ & $\begin{array}{l}\text { Alternativa: } \\
\text { Olimpios, } \\
\text { Éfeso }\end{array}$ & $\begin{array}{l}\text { Olimpios y } \\
\text { Balbileos, } \\
\text { Éfeso }\end{array}$ \\
\hline Mar. & \multirow[t]{2}{*}{$\begin{array}{l}\text { Balbileos y } \\
\text { Adrianeos, } \\
\text { Éfeso }\end{array}$} & \multirow{2}{*}{$\begin{array}{l}\text { Alternativa: } \\
\text { Balbileos y } \\
\text { Adrianeos } \\
\text { Éfeso }\end{array}$} & $\begin{array}{l}\text { Olimpios, } \\
\text { Éfeso }\end{array}$ & & & \multirow{4}{*}{ Panhelenos } \\
\hline Abr. & & & Balbileos & \multirow{3}{*}{$\begin{array}{l}\text { Balbileos } \\
\text { Panhelenos }\end{array}$} & & \\
\hline May. & & Panhelenos & \multirow{2}{*}{ Panhelenos? } & & Panhelenos? & \\
\hline Jun. & Panhelenos & & & & & \\
\hline Jul. & \multirow[t]{2}{*}{ Olímpicos } & \multirow[t]{2}{*}{ Olímpicos } & \multirow[t]{2}{*}{ Olímpicos } & $\begin{array}{l}\text { Olimpios } \\
\text { (Atenas) }\end{array}$ & \multirow[t]{2}{*}{ Olímpicos } & \multirow[t]{2}{*}{ Olímpicos } \\
\hline Ago. & & & & Olímpicos & & \\
\hline
\end{tabular}

$71 \quad$ STRASSER 2010, no indica ninguna especificidad sobre el momento del año en el que se desarrollan las fiestas, su inserción en otoño viene establecida por la interpretación que realiza de su artículo LE GUEN 2010, 213. 


\section{Referencias bibliográficas}

Barns, J. W. B. - Zilliacus, H. (1967): The Antinoopolis Papyri III, Edinburgh.

BeY, E. (1904): "Fouilles de Tralles (102-1903)", BCH 28, 54-92.

BIRLEY, A. R.

(1997): Hadrian, The Restless Emperor, London.

(2004): "Los viajes de Adriano", [en] J. M. Cortés Copete - E. Muñiz (eds.), Adriano Augusto, Sevilla, 59-69.

Bloesch, H. (1997): Griechische Münzen in Winterthur II, Winterthur.

Boatwright, M. T. (2000): Hadrian and the cities of the Roman Empire, Princeton.

Boutet-Lanouette, M. (2007): La vie agonistique dans les cités grecques d'époque impériale. Analyse de l'ajov des Balbilleia d'Éphèse (IIr - III siècle p.C.), Diss., Universitè Laval, Québec.

Burrell, B. (2004): Neokoroi: Greek cities and Roman Emperors, Leiden-Boston.

CAldelli, M. (1993): L'Agon Capitolinus: storia e protagonista dall'istituzione domizianea al IV secolo, Roma.

Campanile, M. (1994): I sacerdoti del koinon d'Asia, Pisa.

Clinton, K. (2008): Eleusis II. Commentary, Athens.

Cortés Copete, J. M.

(1999): "El fracaso del primer proyecto panhelénico de Adriano", DHA 25/2, 91-112.

(e.p.): Palabra del señor. Cartas y documentos del emperador Adriano.

Daux, G. (1976): “La Composition du Conseil Amphictyonique sous l'empire”, [en] F. Chamoux (ed.), Recueil Plassart, Études sur l'antiquité grecque offertes à André Plassart par ses collègues de la Sorbonne, Paris, 59-79.

Feeney, D. (2007): Caesar's Calendar. Ancient Time and the Beginning of History, London.

Follet, S. (1976): Athènes au II et au III siècle. Études chronologiques et prosopographiques, Paris.

Forsythe, G. (2012): Time in Roman Religion. One Thousand Years of Religious History, New York-London.

Geagan, D. J. (1968): "Notes on the Agonistic Institutions of Roman Corinth", GRBS 9, 69-80.

GEBHARD, E. R. (2005): "Rites for Melikertes-Palaimon in the early roman Corinthia", [en] D. N. Schowalter - S. J. Friesen (eds.), Urban Religion in Roman Corinth: Interdisciplinary Approaches, Harvard, 165-203.

Gordillo, R. (e.p.): “La primera celebración de las Hadrianeia de Éfeso”, DHA.

Gouw, P.

(2008): "Hadrian and the Calendar of Greek Agonistic Festivals. A New Proposal for the Third Year of the Olympic Cycle", ZPE 165, 96-104.

(2009): Griekse Atleten in de Romeinse Keizertijd (31 v. Chr. - 400 n. Chr.), Amsterdam.

Graindor, P. (1934): Athènes sous Hadrien, El Cairo.

Guerber, E. (2009): Les Cités grecques dans l'Empire romain. Les privilèges et les titres des cités de l'Orient hellénophone d'Octave Auguste à Dioclétien, Rennes.

Halfmann, H. (1986): Itinera Principum, Geschichte und Typologie der Kaiserreisen im römischen Reich, Stuttgart.

Høנте, J. M. (2000): “Imperial Visits as Occasion for the Erection of Portrait Statues?”, ZPE $133,221-235$. 
Jones, C. P. (2007): “Three New Letters of the Emperor Hadrian”, ZPE 161, 145-156.

KaJaVA, M. (2002): "When did the Isthmian games return to the Isthmus? (Re-reading Corinth VIII.3 n $\left.{ }^{\circ} 153\right) ”$, Classical Philology 97, 168-178.

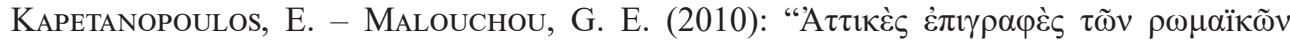

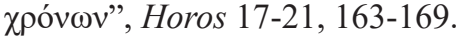

Kent, J. H. (1966): Corinth, Vol. 8, No. 3, The Inscriptions 1926-1950, Princeton-New Jersey.

LÄMmer, M. (1967): Olympien und Hadrianeen im antiken Ephesos, Köln.

LEFÈVRE, F. (1998): L'Amphictionie pyléo-delphique: histoire et institution, Athens.

Le Glay, M. (1976): “Hadrien et l'Asklépieion de Pergamo”, BCH 100/1, 347-372.

Le Guen, B. (2010): “Hadrien, l'Empereur philhellène, et la vie agonistique de son temps. À propos d'un livre récent: Hadrian und die dionysischen Künstler. Drei in Alexandria Troas neugefundene Briefe des Kaisers and die Künstler-Vereinigung", Nikephoros 23, 205-239.

LeHner, M. F. (2004): Die Agonistik im Ephesos der römischen Kaiserzeit, Diss., München.

LeschHOR, W. (1998): "Die Verbreitung von Agonen in den östlichen Provinzen des Römischen Reiches", Stadion 24, 31-58.

Magie, D. (1950): Roman Rule in Asia Minor. To the End of the Third Century after Christ, Princeton.

Meritt, D. B. (1931): Corinth, Vol. 8, No. 1, Greek Inscriptions 1896-1927, Cambridge.

Mikalson, J. D. (1975): The Sacred and Civil Calendar of the Athenian Year, Princeton.

Moretti, L. (1953): Inscrizioni Agonistiche Greche, Roma.

OLIVER, J. H.

(1941a): “Greek and Latin Inscriptions", Hesperia 10/3, 237-261 (http://dx.doi. org/10.2307/146562).

(1941b): The Sacred Gerousia, Athens.

(1970): Marcus Aurelius: Aspects of civic and cultural policy in the East, Princeton.

Petzl, G. - Schwertheim, E. (2006): Hadrian und die dionysischen Künstler. Drei in Alexandria Troas neugefundene Briefe des Kaisers und die Künstler-Vereinigung, Bonn.

Pleket, H. W. (1975): “Games, Prizes and Ideology”, Stadion 1, 49-89.

Pouilloux, J. (1980): “Les épimélètes des Amphictions: tradition delphique et politique romaine", Mélanges Pierre Wuilleumier, 281-299.

Remiusen, S. (2011): “The So-Called 'Crown-Games': Terminology and Historical Context of the Ancient Categories for Agones", ZPE 177, 97-109.

Rigsby, K. J. (2010): “The Schedule of the Eleusinia", Mnemosyne 63, 289-297.

Romano, D. G. (2005): "Urban and rural planning in roman Corinth", [en] D. N. Schowalter - S. J. Friesen (eds.), Urban Religion in Roman Corinth: Interdisciplinary Approaches, Harvard, 25-64.

Roueché, CH. (1993): Performers and Partisans at Aphrodisias in the Roman and Late Roman Periods, London.

RüPke, J. (2011): The Roman Calendar from Numa to Constantine. Time, History and the Fasti, Oxford.

Samuel, E. A. (1972): Greek and Roman Chronology. Calendars and years in Classical Antiquity, München.

SÁnchez, P. (2001): L'amphictionie des Pyles et de Delphes. Recherches sur son role historique, des origins au II siècle de notré ère, Stuttgart. 
Schmidt, St. (2009): “Zum Treffen in Neapel und den Panhellenia in der Hadriansinschrift aus Alexandria Troas", ZPE 170, 109-112.

Scotт, K. (1931): "The Honorific Months in Greek and Roman Calendars", Yale Classical Studies 2, 199-278.

SHEAR, J. L.

(2001): Polis and Panathenaia: The History and Development of Athena's Festival, Diss., University of Pennsylvania.

(2012): "Hadrian, the Panathenaia, and the Athenian Calendar", ZPE 180, 159-172.

Slater, W. (2008): "Hadrian's letters to the athletes and Dionysiac Artists concerning arrangements for the "circuit" of games", JRA 21, 610-620 (https://doi.org/10.1017/ S1047759400005055).

Spawforth, A. - Walker, S. (1985): "The World of the Panhellenion I: Athens and Eleusis", JRS 75, 78-104 (http://dx.doi.org/10.2307/300654).

Stern, S. (2012): Calendars in Antiquity. Empires, States and Societies, Oxford.

STRASSER, J.-Y.

(2000): Les concours grecs d'Octave Auguste aux invasions barbares du 3ème siècle, Diss., Université Paris X Nanterre.

(2010): “'Qu'on fouette les concurrents....': à propos des lettres d'Hadrien retrouvées à Alexandrie de Troade", REG 123/2, 582-622.

Svoronos, J. N. (1923-1926): Les monnaies d'Athènes, Munich.

Syme, R. (1988): “Journeys of Hadrian”, ZPE 73, 159-170.

WeBER, W. (1907): Untersuchungen zur Geschichte des Kaisers Hadrianus, Lepzig.

WeIr, R. (2004): Roman Delphi and its Pythian Games, Oxford.

Wörrle, M. (1992): "Neue Inschriftenfunde aus Aizanoi I. Eine Bruckenweihung des Eurykles", Chiron 22, 337-349. 